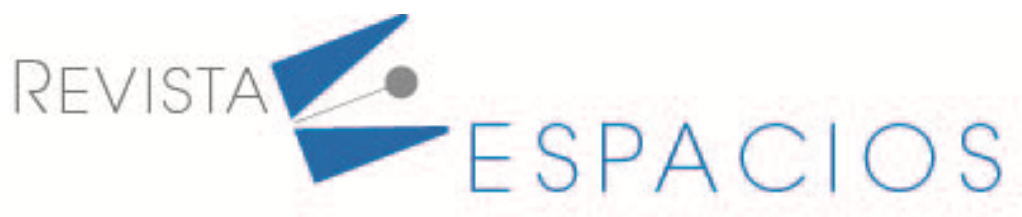

\title{
Familiness as determinant of operational risk: a bayesian analysis
}

\section{Familiness como determinante del riesgo operacional: un análisis bayesiano}

\author{
DÁVILA-ARAGÓN, Griselda ${ }^{1}$ \\ RAMÍREZ-PÉREZ, Héctor $X{ }^{2}$ \\ RIVAS-ACEVES, Salvador ${ }^{3}$
}

\begin{abstract}
This research proposes a Bayesian Network (BN) methodology to analyze variables in risk for family firms and measure how exposed they are to Operational Risk (OR). The purpose is to identify variables that cause OR through the use of a BN in an environment of low or no-information to be able to measure. Results show elements that would increase OR if they are not identified or managed correctly, such as: type of ownership, family values, organizational structure and succession plans.

key words: bayesian network, operational risk, private family business, firm behavior

Resumen

Se propone una metodología para analizar el riesgo operacional (RO) en empresas familiares. El objetivo es identificar elementos de Familiness que pueden causar riesgo operativo mediante una Red Bayesiana, bajo ambientes de poca o nula información. Los resultados muestran que hay elementos de Familiness que incrementan el RO si no son identificados o correctamente administrados, por ejemplo: tipo de propiedad, valores familiares, estructura organizacional, sucesión, entre otros.

Palabras clave: red bayesiana, riesgo operacional, empresas familiares, desempeño empresarial
\end{abstract}

\section{Introduction}

A company is an organization competing in a market with the aim to satisfy its customers and create value for the society and the economy. Its success is measured according to the benefits generated for its stockholders. Businesses can be classified according their industry, origin of the capital, size, legal status, or ownership and management of the stockholders. The latter is the type of classification that refers to Family Businesses (FB), when the companies are owned or managed by family members of the same family. There are companies owned by investment funds or private stockholders or managed by professional executives, however, those are an exception. The majority of businesses started as family businesses; in these types of firms, there are also public

\footnotetext{
${ }^{1}$ Profesor-investigador, Escuela de Ciencias Económicas y Empresariales, Universidad Panamericana, gdavila@up.edu.mx

${ }^{2}$ Profesor-investigador, Escuela de Ciencias Económicas y Empresariales, Universidad Panamericana, heramire@up.edu.mx

${ }_{3}^{3}$ Profesor-investigador, Escuela de Ciencias Económicas y Empresariales, Universidad Panamericana, srivasa@up.edu.mx
} 
organizations in which their founders or members of the main family keep control of the company with the goal to succeed the firm to next generations.

One characteristic of family versus non-family firms is the relationship among family members in which they share common values, believes, and family norms (Leach, 2009). Family Firms are present in all economic levels; they are of different sizes, and different level of professionalization, but common element is the great influence a family has over the company. Unlike non-family firms, FB are the majority in almost every country, therefore they have an important responsibility on the economic development of the countries. In Mexico, FB compose more than five million companies and employ over 27 million people (INEGI, 2011). From this universe, micro, small, and medium firms, represent $99 \%$ of the total number of companies, with 5.4 employees on average, and provide $50 \%$ of the GDP. In the US, the estimation of FB is of $95 \%$. In general, a Family Business starts because of the desire of its founder to create wealth for his/her family and the future generations. Many family firms begin without a structure or professional procedures, therefore its mortality rate is high; few organizations survive to the second generation, and a minority to the third one. They face, as any other business organization, economic and social problems, but in addition, they deal with a highly complex management due to the family involvement. The management team might find difficult to reach its objectives and goals because of conflict of interests from family members working in the organization.

Within the block of family businesses, we find public and private family firms, with the latter as the most common form of organization playing a large role in the world's economies (Colli, 2003). Although private family firms dominate the economic landscape of the planet, more than 80 per cent of the management literature has been focused on publicly traded firms partly due to easier access to reliable data on variables of interest. (Sharma \& Carney, 2012). However, family businesses are the ones that require more help and to expand to expand the knowledge and understanding about them; many studies proved that when private, family firms have lower financial results than non-family ones (Martínez, Stöhr, \& Quiroga, 2007; Sharma, Chrisman, \& Gersick, 2012; Stewart \& Hitt, 2012). This reality is different when comparing public businesses; many studies have shown that family firms outperform non-family firms (Allouche, Amann, Jaussaud, \& Kurashina, 2008; Anderson \& Reeb, 2003; Carney, Van Essen, Gedajlovic, \& Heugens, 2013; Corbetta, 1995; Gueye \& Simon, 2010; Le Breton-Miller \& Miller, 2006; Martin-Reyna \& Duran-Encalada, 2012; Martínez, Stöhr, \& Quiroga, 2007). The challenge is to identify the main elements from public family firms that help to outperform public non-family firms and to define if those elements could be applied to private family firms. One of those elements might be the lack of institutionalized process and a formal management.

Due to the fact that family businesses have an additional variable versus non-family firms such as family relationships which might lead to informal management or to accept family desires over the organization interests, it is important to recognize that the risk of these types of companies for disappearing in a short period of time increases. Therefore, Operative Risk (OR) in FB is constantly present. For this reason, it is important to identify, manage, and quantify the OR through internal control systems. Also, it is relevant to recognize the difficulty that represents to access to the information of family firms when private because family business owners and managers are not required to share company's info; there is also a lack of reliable databases.

Currently, there is not any law that compels a non-financial organization to analyze, evaluate, and quantify the OR. This research proposes a Bayesian Networks (BN) methodology to analyze the variables in risk for family firms and measure how exposed they are to the operative risk. This study is relevant because it is the first proposal of a methodology to measure the operative risk in private family firms. The purpose is to define the variables that cause the operative risk in an environment of low or no- information to measure, through the use of a Bayesian network. Some general questions are: Which elements of the regular operation cause OR? How is the interaction among these elements? Which is the best way to avoid the impact on OR? To solve these 
questions there are some elements that would increase the OR if not identified or managed correctly such as: type of ownership, family values, organizational structure, succession plans, among others. It can be expected that a deficient organizational structure and the lack of succession plans might lead to increase the OR.

\subsection{Theoretical framework}

Family firms have been studied in the last decades because their economic importance in the world, in developed and developing countries. First researches on FB showed up in 1975 with the appearance of the book "A Guide for the Business Owner and His Family" written by León Danco; other projects (Moore, 1951; Cochran, 1959; Davis, 1968) pretended to define the family business concept, their success and failure factors, and the economic role these firms play in the economy of a country. Many authors agreed that the family firm is the most common and the oldest type of commercial organization in the world. They play a major role in the growth and development of the economy of a country and jobs creation. Family Businesses are from different sizes: from small to multinational corporations. That is also the case for the FB in Europe and the US where the presence of family firms, job creation, and wealth generation are very important (Ward, 2007).

Robbins and Coulter (2000) point that an organization is a structured group of people with the objective to achieve a specific goal and with some characteristics: 1) a distinctive purpose, 2) formed by people, and 3) a specific structure that allows its members to develop their job. In the case of a family firm, it is the family the one that establishes the main structure. Gersick et al. (1997) defined a family firm as a three-dimensional organization in which family, business and ownership intersect. Ramírez and Fonseca (2010) consider a family business as an organization in which a family owns all the shares, family members occupies management positions, and more than one generation of the family participate at the same time. Soto Maciel (2013) states a family firm as an organization in which the majority of the voting rights are in the hands of the controlling family, including the founder, with the aim to pass succeed the business to the next generation, with the commitment of keeping the assets of the family firm to maintain family unity through the property. Bañeguil, Barroso, and Tato (2011) define it as a highly complex social organization, where "business" and "family" live together as independent subsystems, which might face some conflicts. Despite the lack of consensus for a general definition for a family firm, the majority of the researches associate a family firm with ownership and management in possession of the controlling family.

Family Businesses enclose some characteristics that make them unique: 1) ownership is in one controlling family; 2) the power executed by the family over the business, normally includes top executive positions in the management board, and 3) the desire the keep the firm in family hands (Gallo, 1995). In addition, Tagiuri and Davis (1996) express that a family firm exists if there are three interconnected subsystems: ownership, family, and business. Based on the definition of Gersick et al. (1997) it was created the three-circle model which describes the family firm system formed by independent, but related subsystems: business, ownership, and family. Each subsystem maintains limits that differentiate with the other two and from the environment of the family firm. The model includes a complex and dynamic social system in which the subsystems integrate among themselves through reciprocal adjustments. This dynamic allows a different reality and perspective between the family members and the business. The absence of clear limits among family, ownership, and business might create unsteadiness of the subsystems; therefore, balance, limits, and equilibrium are important to have among the three dimensions (Aira, 2016). The present research is based on the three-circle model.

Family involvement in ownership and management has some advantages: decision making process might be more effective due the similarity of interests among family members regarding ownership and management of the firm related to the family which might lead to increase the value of the firm (Castrillo \& San Martín, 2007). Family firms that privilege family rights (for example, employment as a right for family members from birth), might create a situation where knowledge, experience, and skills were irrelevant for the hiring and succession 
process. If a family firm privileges the business (for example performance and profits) might create a situation in which family members would decrease their interest on the firm. If a family firm privileges ownership, the organization would focus its attention over the investment and risk of decision making (Poza, 2005).

Family firms require of people that manage the organization. As any other institution where people collaborate, technology systems intervene, and processes are present, the operative risk is present; family firms are not the exception. The operative risk is the oldest type of risks and in recent years the interest to understand this phenomenon has growth, mainly from financial firms, because there have been a bigger number of events related to the operative risk (Dávila, Ortiz \& Cruz, 2016).

The likelihood of human errors while operating systems that could lead to a shutdown of the operations in the firm has always existed. However, it was not until until recently that these types of risks were classified as a specific risk and financial institutions have recognized the lack of understanding and tools to measure them. From then, there is a special focus to define, manage, value, and quantify the operative risk considering the complex process because of the multiple factors that are involved in the operative risk (Dávila et al. 2016). The operative risk is defined as the potential loses because of errors in the internal control systems, operations processes, transfer of information, administrative or legal resolutions, frauds, and thefts (CUB, 2005).

\section{Bayesian Network Methodology}

Bayesian Networks are the result of statistic modeling, engineering and artificial intelligence convergence (Cowell, Verrall \& Yoon, 2007). The BN analyze a problem through a set of variables and the dependency relationships between them. Actually, they are a mathematical structure that is used to represent a process and its dependencies (cause and effect), assigning weights and probabilities of occurrence. They are an acyclic directed graph; the nodes represent the variables of interest and the edges are the causal or influence links between the variables (Madsen \& Kjaerulff 2008). Each node is associated with a probability table, as well as a statistical distribution or a parameterized function. In the case of a node probability table, the relationship is governed by a set of conditional probability values that model the uncertain relationship between the node and its parent nodes together with any uncertainty present in that relationship.

Bayesian models serve both to solve problems from a descriptive as well as a predictive perspective. As a descriptive method, they focus on discovering dependency / independence relationships, so they sometimes complement or even exceed the association rules. Regarding the predictive function, it is circumscribed to Bayesian techniques as classification methods. According to Mitchell (1997), Bayesian methods are one of the techniques that have been used the most in the problems of artificial intelligence, machine learning and data mining. This is a very valid and practical method to make inferences with the data available, which implies inducing probabilistic models that, once calculated, can be used with other data mining techniques (Beltran, Muñoz \& Muñoz, 2014). This makes BN a potential tool to include the subjective opinion of experts and data observed in cause and effect models. By combining expert qualitative data with statistical data it is possible to reflect an underlying causal structure of the subject of analysis.

Its main advantage is that they allow reasoning under uncertainty and combine the advantages of intuitive visual representation with a mathematical basis of Bayesian probability; with them it is possible to articulate dependencies between different variables and systematically propagate the impact of the evidence on the probabilities of uncertain results (Neil, Fenton \& Tailor, 2005). The key to a successful design of a Bayesian Network is the significant decomposition of the domain of the problem into a set of causal or conditional propositions. The partial specifications of the model that are significant in the domain of the expert are divided and taken (Chonawee, Kenyon, \& Heusler, 2006). Subsequently, the probability table of the node is modeled for each variable (node), which can be done using historical data and in the absence of these, requesting an expert 
to provide a series of subjective estimates, which will ideally be based on knowledge and the experience (Cowell, Dawid, Lauritzen \& Spiegelhalter, 1999). Applying the BN methodology to the evaluation of the OR in Family Business (FB) implies identifying the risk factors to which the private FB are exposed and the dependency relations between them.

The RB are based on the Bayes Theorem that can be interpreted as the "posteriori" probability $\mathrm{P}(\mathrm{B} \mid \mathrm{A})$ being equal to the a priori probability $P(B)$ multiplied by the reason $\frac{P(A \mid B)}{P(A)}$; that is, the previous information about $B$ can be used to check the probability of $\boldsymbol{B}$, from:

$$
P(B \mid A)=\frac{P(A \mid B) P(B)}{P(A)} .
$$

By applying the Bayes Theorem to distributions on the parameters of a model, for example, where observations $\underline{\boldsymbol{x}}$ are taken from the sample of a population with a probability distribution defined for the parameter $\boldsymbol{\theta}$ it can be obtained:

$$
P(\theta \mid \underline{x})=\frac{P(\underline{x} \mid \theta) P(\theta)}{P(\underline{x})} .
$$

Under this scenario, $\boldsymbol{P}(\boldsymbol{\theta})$ is the information "a priori" of the population and is subjective. In this case it is an unconditional probability that represents the uncertainty about the parameter $\boldsymbol{\theta}$. The function $\boldsymbol{P}(\underline{\boldsymbol{x}} \mid \boldsymbol{\theta})$ is commonly called the likelihood of the data set $\underline{x}$, denoted also as $\boldsymbol{L}(\underline{\boldsymbol{x}} \mid \boldsymbol{\theta})$ and it is interpreted as the probability of observing a set of certain data $\underline{x}$ given that certain characteristics of the population $\theta$ are true. By combining the subjective information with the empirical observations (the information "a priori" and the likelihoods), the posterior probability is obtained, that is, the probability that the parameter $\theta$ will take certain values given that the observations $\underline{\boldsymbol{x}}$ have been made, which is denoted as $\boldsymbol{P}(\boldsymbol{\theta} \mid \underline{\boldsymbol{x}})$. If $\boldsymbol{P}(\underline{\boldsymbol{x}} \mid \boldsymbol{\theta}) \boldsymbol{P}(\boldsymbol{\theta})$ is added, the marginal probability of $\underline{x}$ is obtained.

$$
P(\underline{x})=\sum P(\underline{x} \mid \theta) P(\theta) .
$$

The unconditional probability of the data $\boldsymbol{P}(\underline{\boldsymbol{x}})$, serves as a scale constant. The rule can be re expressed as follows:

$$
P(\underline{x}, \theta)=P(\underline{x} \mid \theta) P(\theta)=L(\theta \mid \underline{x}) P(\underline{x}) .
$$

In other words, the joint distribution of the observed data and the parameters is equal to the density of the observations given the parameters by the density of the parameters. This is equivalent to the a posteriori distribution of the parameters, given the observed data, by the marginal density of the data. Consequently $\boldsymbol{L}(\boldsymbol{\theta} \mid \underline{\boldsymbol{x}})$ is the a posteriori distribution function. In this way, the posterior distribution can be expressed as:

$$
P(\theta \mid \underline{x}) \propto L(\underline{x} \mid \theta) P(\theta) .
$$

Intuitively, the Bayesian idea says that conjectures about the population are a combination of the prior knowledge of the population and the observations made about that same population. It is not only the "a priori" information that has influence; The degree of confidence in the expert's information also has an effect. The Bayesian analysis simply formalizes this concept: later densities take into account to a greater or lesser degree the information of the beliefs depending on the trust that is placed on it. 
In a graphical Bayesian Network, nodes represent the variables of interest and edges are the causal or influence links between variables, in each node there is an associated probability table, a statistical distribution or a parameterized function of the variables, see Cardozo (2011). In the case of a probability table, the relationship is governed by a set of conditional probability values that model the uncertain relationship between the node and its parent nodes together with any uncertainty present in that relationship. The mathematical definition of a BN is given by the following elements: a) a set of random variables connected by a set of arcs (graphic model); b) Each variable has a finite set of mutually exclusive states associated with it; $c$ ) the variables together with the directed arcs form an Acyclic Directed Graph. In Figure 1, case a): $\boldsymbol{x}_{\mathbf{1}}$ and $\boldsymbol{x}_{\mathbf{2}}$ are called nodes and represent the variables $x_{1}$ y $x_{2}$. The directed edge of $x_{1}$ and $x_{2}$ implies a causality relationship between $x_{1}$ and $\boldsymbol{x}_{2}$. Indicates that a change in what is known from $x_{1}$ causes a change in what is known from $x_{2}$. This change is usually the result of new information that arrives on $\boldsymbol{x}_{\mathbf{1}}$. This new information is called evidence. This causality between the variables gives names to the nodes, so the node $\boldsymbol{x}_{\mathbf{1}}$ is called "father" and the node $\boldsymbol{x}_{\mathbf{2}}$ "child". The causal relationship that exists between $x_{1}$ and $x_{2}$ means that the joint distribution can be expressed as the product of the probability of $x_{1}$ and the probability of $x_{2}$ conditioned by $x_{1}$, that is: $P\left(x_{1}\right) P\left(x_{2} \mid x_{1}\right)$ that is the basic probability relation in a graphic form.

Figure 1

Various graphic models directed

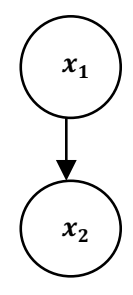

a)

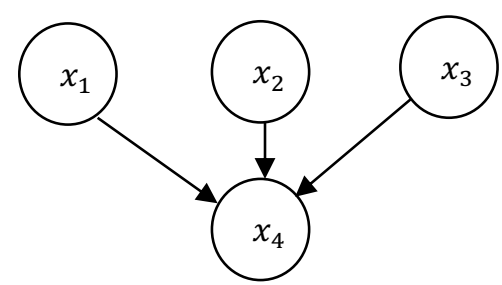

b)

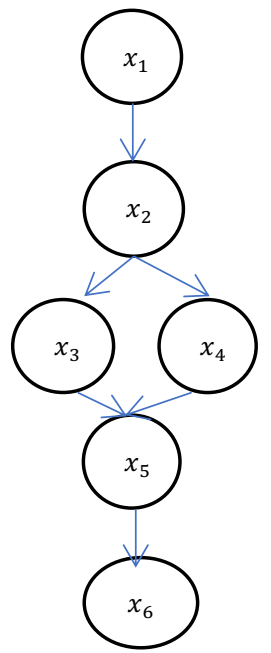

Source: own elaboration

In Figure 1, case b): for each variable $\boldsymbol{x}_{\mathbf{4}}$ with "parents" $\boldsymbol{x}_{\mathbf{1}}, \mathbf{x}_{2}, \ldots \mathbf{x}_{\mathbf{n}}$ there is an associated probability defined by $\mathbf{P}\left(\boldsymbol{x}_{\mathbf{4}} \mid \boldsymbol{x}_{1}, \mathbf{x}_{2}, \ldots \mathbf{x}_{n}\right)$. If $\boldsymbol{x}_{\mathbf{4}}$ does not have "parents" the probability $\boldsymbol{x}_{\mathbf{4}}$ will be independent. In Figure 1 , case c): Be $\boldsymbol{X}=\left\{\boldsymbol{x}_{\mathbf{1}}, \boldsymbol{x}_{2}, \ldots \boldsymbol{x}_{\boldsymbol{n}}\right\}$ a random variable with a joint distribution function defined by $\boldsymbol{P}(\boldsymbol{X})=\boldsymbol{P}\left(\boldsymbol{x}_{\mathbf{1}}, \boldsymbol{x}_{2}, \ldots \boldsymbol{x}_{\boldsymbol{n}}\right)$, with the characteristic that $\boldsymbol{P}(\boldsymbol{X})$ grows exponentially with the number of variables, and be $\boldsymbol{p}\left(\boldsymbol{x}_{\boldsymbol{i}}\right)$ the set of values taken by the "parent" nodes of the variable $\boldsymbol{x}_{\boldsymbol{i}}$; then, the total joint distribution is given by:

$$
P(X)=P\left(x_{1}, x_{2}, \ldots x_{n}\right)=\prod\left(x_{i} \mid p\left(x_{i}\right)\right) .
$$

And the total joint probability is given by:

$$
P(X)=P\left(x_{1}, x_{2}, x_{3}, x_{4}, x_{5}\right)=P\left(x_{1}\right) P\left(x_{2} \mid x_{1}\right) P\left(x_{3} \mid x_{2}\right) P\left(x_{4} \mid x_{2}\right) P\left(x_{5} \mid x_{3}, x_{4}\right) P\left(x_{6} \mid x_{5}\right) .
$$

The factorization of the joint distribution in a conditional distribution for the node $\boldsymbol{x}_{\mathbf{5}}$ given its "parents", is verified in the following expression: 


$$
P\left(x_{5} \mid x_{4}, x_{3}, x_{2}, x_{1}\right)=P\left(x_{5} \mid x_{3}, x_{4}\right) \text {. }
$$

Consequently, Bayesian Networks provide a compact representation of $\boldsymbol{P}(\boldsymbol{X})$, factoring the joint distribution into a local conditional distribution for each variable given their "parents". As a recall, the key to a successful design of a BN is the significant decomposition of a domain of the problem into a set of causal or conditional statements about the domain. Instead of carrying out the laborious and difficult task of calculating the joint probability distribution of all the variables of interest, the "divide and conquer" principle is applied and the partial specifications of the model that are significant in the domain are taken of the expert. Subsequently, the probability table of the node is modeled for each variable, which can be done using historical data or only asking an expert to provide a series of subjective estimates, which will ideally be based on knowledge and experience. Based on the above, for the present research, the BN is designed for private family businesses.

\subsection{Construction of the Bayesian Network}

To define the risk variables, sessions were held with experts in family businesses, a sample composed of 197 respondents with the following distribution: $4 \%$ were presidents, $2 \%$ owners, 38 per cent CEO's, $20 \%$ directors, $15 \%$ managers and $19 \%$ others. The results with respect to the selection of the variables are shown in Table 1. The definition of the variables is justified below. The FB in question are formed in different ways according to the property: a) they can be owned by a family, even a single owner that operates at the same time, b) the foundation and the property combine more than one generation and the transition from one generation to another may occur, or, c) may have been founded by a family and incorporate non-family employees in the management. One of the most important and critical processes of FB is family succession, understood as a process that ends with the transmission of decision power and ownership to the next generation if its purpose is to guarantee the continuity of the organization. This requires maintaining the address of the company and the property in the family. Several studies indicate that few companies survive the transition between generations (Manzano \& Ayala, 2002).

In general, only between $25 \%$ and $30 \%$ last from the first to the second generation, between $9 \%$ and $15 \%$ manage to continue to the third generation, and $6 \%$ or less manage to pass from the third to the fourth generation (Neubauer \& Lank, 1998). While the founder maintains control of the family business there is a high degree of control over the business (Kuratko, Foss \& Vanalst, 1994), making the family the main axis by instituting each of its members and emphasizing the mission and vision of the company; base and promote its principles so that family members can see the organization as an opportunity for growth while preserving the roots and values of the family unit. Values are norms of behavior and attitudes that govern the behavior of each person about what is good or bad. Personal values are those that the individuals associate in their belief system that governs their life and relationships with other people, while family values are transmitted from parents to children through communication and experiences; therefore, the importance of considering them as the foundation of organizations and families (Esquivel \& Aguilar, 2002). 
Table 1

Definition of variables and nodes

\begin{tabular}{|l|l|l|}
\hline \multicolumn{1}{|c|}{ Variable } & \multicolumn{1}{|c|}{ - Definition } & \multicolumn{1}{c|}{ - Dimension } \\
\hline Property & Property Distribution & \multicolumn{1}{c|}{$\begin{array}{l}\text { Family } \\
\text { Family and external }\end{array}$} \\
\hline Succession & $\begin{array}{l}\text { Transition from one generation to another. } \\
\text { Continuity throughout different generations }\end{array}$ & $\begin{array}{l}\text { Planned } \\
\text { None planned }\end{array}$ \\
\hline Family Values & Aligned to the values of the company & $\begin{array}{l}\text { Yes } \\
\text { No }\end{array}$ \\
\hline $\begin{array}{l}\text { Organizational } \\
\text { Culture }\end{array}$ & Culture built by the company & $\begin{array}{l}\text { Exist } \\
\text { Not Exist }\end{array}$ \\
\hline Financing & Obtaining capital for new investments & $\begin{array}{l}\text { Internal } \\
\text { External }\end{array}$ \\
\hline Board of Directors & Definition of strategy and long-term plans & $\begin{array}{l}\text { Exist } \\
\text { Not Exist }\end{array}$ \\
\hline $\begin{array}{l}\text { Organizational } \\
\text { Structure }\end{array}$ & $\begin{array}{l}\text { Management positions and identified and defines } \\
\text { responsibilities }\end{array}$ & $\begin{array}{l}\text { Exist } \\
\text { Not Exist }\end{array}$ \\
\hline $\begin{array}{l}\text { Professionalization } \\
\text { Planning and controlling the growth of family and } \\
\text { non-family employees }\end{array}$ & $\begin{array}{l}\text { High } \\
\text { Medium } \\
\text { Low }\end{array}$ \\
\hline
\end{tabular}

Source: own elaboration

If the family does not recognize the barriers and limits, effective communication will be difficult and it will generate informality, favoring the demarcation of responsibilities with respect to operational failures. There will be no responsible for the good or bad and it would be difficult to find the causes that originated the event, making it impossible to learn from mistakes and improve. To professionalize the management of the FB is to leave aside the intuitive methods of family management and adopt the planning and control of the growth of family and non-family employees, applying strategic methods. It implies the hiring of professional managers, belonging or not to the family, who contribute their experience and training in the specific area that they wish to promote (Barroso, 2014).

There are companies that usually grant special privileges for employees, members of the family, generating a culture of injustice towards non-family employees. The low valuation of non-family employees precludes the development of a professional management, and the staff is discouraged by not being able to reach better positions within the organization. It is common for employees to feel ignored and threatened by decisions of family members. It may be more difficult to retain qualified professionals if there is no clear and competitive career development plan with respect to family employees. Once the eight variables of the Bayesian network were described, in order to carry out the structure of the model it was necessary to define the domain of the network, which consisted in designing a model that would allow private FB to evaluate their exposure to operational risk. Therefore, the next step was to identify the important variables or nodes, which represents a substantial part of the network design; this implied the total knowledge of the process to be able to decompose it in all its phases and to select the nodes to establish the relations between them.

With the selected variables, the graphic model of the causal relationships was designed, obtaining a network with one parent node and seven child nodes to measure the variable of interest: Operational Risk. The resulting relationships are plotted in Figure 2. After the creation of the Bayesian Network, the next step is to validate the model with the commission of experts in administration of FB. In the next section we will describe the interrelation between the nodes, as well as the assigned a priori probabilities and with this the model is 
propagated to obtain the posterior probabilities and, therefore, establish an operational risk assessment to which they are exposed.

Several of the problems in the family business derive from the conflicts that arise between the values of the family and those of the company. "The spirit of the family will determine, to a large extent, the dominant attitudes, norms and values in the company"; "the values expressed by the family members will become a common objective for the employees and will help them to identify and commit themselves" (Kets de Vires, 1993). The values of the company reflect the principles of the family and are transmitted from generation to generation through example and education. Therefore, the values of the founder are the starting point to form the values of the company and are critical for the unity and well-being of the company, the family, its workers and society. The values and beliefs will allow the family business to form an organizational culture, to endure and position itself over time, and to legitimize the company and its ethics as part of the corporate identity (Fernández, Junquera \& Ordiz, 2003).

The culture is a complex and multidisciplinary set of everything that constitutes the common life of the people, making itself present in the social customs and the patterns of behavior of the individuals, giving origin to a cultural relation. Organizational culture is defined as an organizational system of shared functions and values assigned to behavioral models. They are transmitted to the members of an organization based on the beliefs that influence within it and are focused on the administration to generate competitiveness. The organizational culture molds and builds the orientation of companies to the market: customer orientation, orientation to competition and orientation to profitability and vision (Narver \& Slater, 1990); The above could represent a competitive advantage of the FB.

Another critical element in FB is the capital to finance growth. For the most part, FB are characterized by having a stable capital structure and new investments are usually made with family investments, which allows a strong financial stability and a financial leverage below the rest of the organizations, being therefore less vulnerable to fluctuations in economic cycles. Giménez (2002) states that this practice tends to lead to two types of capital raising: 1) self-financing, where investments are not made until domestic financing has been obtained and 2) resistance to access the capital market through the fear of including investors outside the family. However, these practices may cause project financing, causing economic loss to the organization or slow growth.

The Board of Directors in a company must define the set of principles, structures and processes that will help the owner family to materialize their long-term vision in actions linked to the family group. Communicate the values, mission and long-term vision of the family to all its members; keep informed about the main achievements, challenges and strategic directions of the company to the family members that work in it; communicate the rules and decisions that could affect employment, dividends and other benefits that the family usually obtains from the company; Establish formal communication channels to share ideas and problems, and allow the family to come together to make decisions.

In general terms, it will create trust between the family members, increasing the continuity of the family business throughout different generations and regulating the conflicts of interest of the different agents that participate in the company: managers, shareholders, employees and creditors. A good Board of Directors contributes to sustainable economic development by improving the performance of companies and increasing their access to external capital (IFC, 2011). A very low percentage of managers of FB recognizes that there is a clear organizational structure in the organization and that management positions and responsibilities are identified and defined (Masulis, Kien \& Zein, 2011). 


\subsection{Quantification of the Bayesian Network}

Processes are developed and managed by people, they are the ones who cause OR events by doing something they should not have done or not done. It is this intervention of people in the processes of operation one of the reasons that makes the quantification of risk so complicated. Another reason for the quantification to be complicated is the lack of statistically reliable information; there are few data that are registered for private FB. The Bayesian Networks are a viable alternative for the analysis of risks in conditions of insufficient information since they allow the incorporation of initial information through an a priori probability distribution, through which subjective information can be included in decision making, such as: expert opinion, the judgment of analysts or the beliefs of specialists.

To quantify the Bayesian Network, a set of experts in family businesses was used and the a priori probabilities were defined for each node; Each node in the network has a conditional probability table that determines the level of interrelation of the nodes. These probabilities were built on the information provided and validated by the group of family business experts. The information obtained by the experts is incorporated into the model in the initialization phase and the algorithm is propagated to obtain the new marginal distributions a-posteriori. Performing the process manually is extremely laborious, so the GeNle software was used to feed the nodes and start the calculation process.

Figure 2

Graphic model of causal relationships

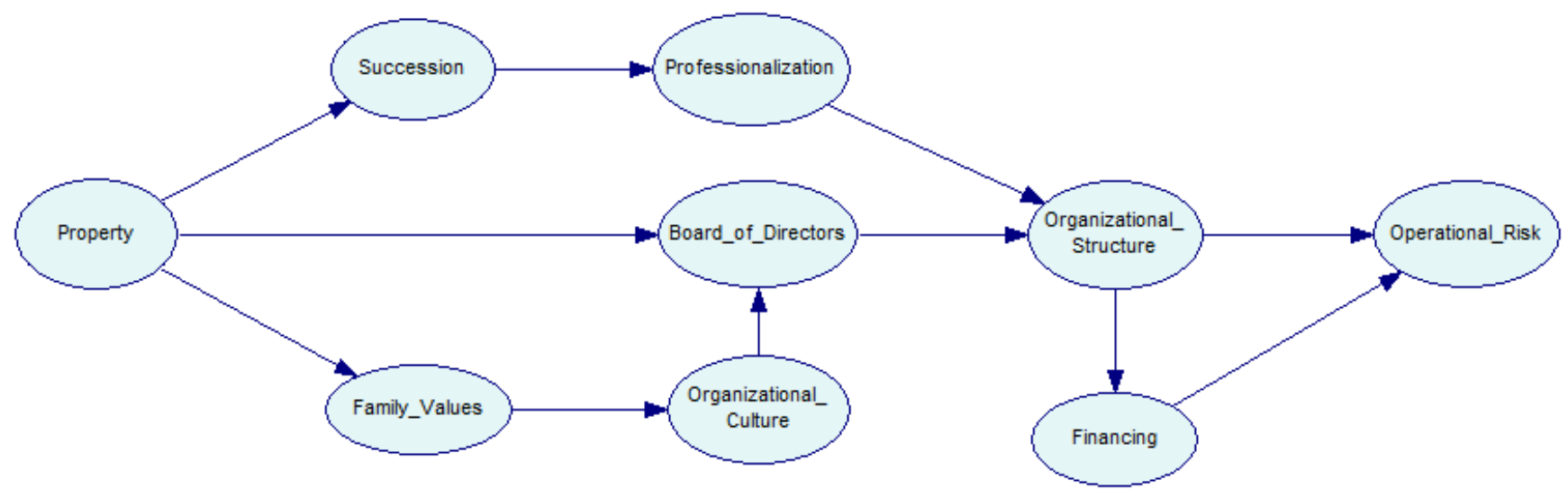

Source: own elaboration with GeNle software

With the above, the Bayesian network is ready to model the OR and know the current state of the company, using the a priori distributions for each node, propagate the information and obtain the probabilities a-posteriori. Figure 3 shows the posterior probabilities after propagation. Once the Bayesian network is built, it can be executed using an appropriate propagation algorithm. When the Bayesian network is executed, the effect of the data entered into one or more nodes is propagated throughout the network, in any direction and the marginal distribution of the nodes is updated. This makes the model ideal for a scenario analysis. Under this scenario, $97 \%$ of the FB have family members exclusively as owners and only three per cent are companies with the participation of partners outside the family nucleus. With a probability of $74 \%$, family values are aligned with the values of the company and with a probability of $26 \%$, this is not the case. With $52 \%$ probability, functions and values focused on administration are based on the behavior transmitted by family members to the general staff (organizational culture) and with $48 \%$ probability they are not.

The definition of the strategy and the long-term plans carried out by the Board of Directors exist in the FB with a probability of $20 \%$ and with a probability of $80 \%$ there is no Board of Directors and, therefore, it is possible that the strategy is not clearly defined. With a probability of $16 \%$, the managerial positions and responsibilities of 
each employee are defined and with a probability of $84 \%$ the organizational structure is not clear. With a probability of $63 \%$, the FB will resort to internal financing and with a probability of $37 \%$ to financing from external sources.

In terms of succession, understood as the planning for the transition from one generation to another that gives continuity to the company in the long term, with a probability of $17 \%$ there is an established plan and with a probability of $83 \%$ there is no clarity in the transmission power. With a probability of $25 \%$ the employees, members of the family and not members of the family, have a high degree of professionalization, with a probability of $28 \%$, their level of professionalization is medium and with a probability of $47 \%$, it is low or null. Under these conditions, the probability of an unfavorable event in the family business originated by the people who work in it or by the processes that affect the operation of the company to the point of bankruptcy is $64 \%$ probability; with probability of $17 \%$ the occurrence of the risk is medium and with a probability of $19 \%$ it is low. Hence, a possible explanation for the fact that the majority of the FDs have such a high mortality rate and few that survive from generation to generation. These results were considered as a baseline scenario to perform the scenario analysis presented in the next section.

Figure 3

Graphic model of a posteriori probabilities

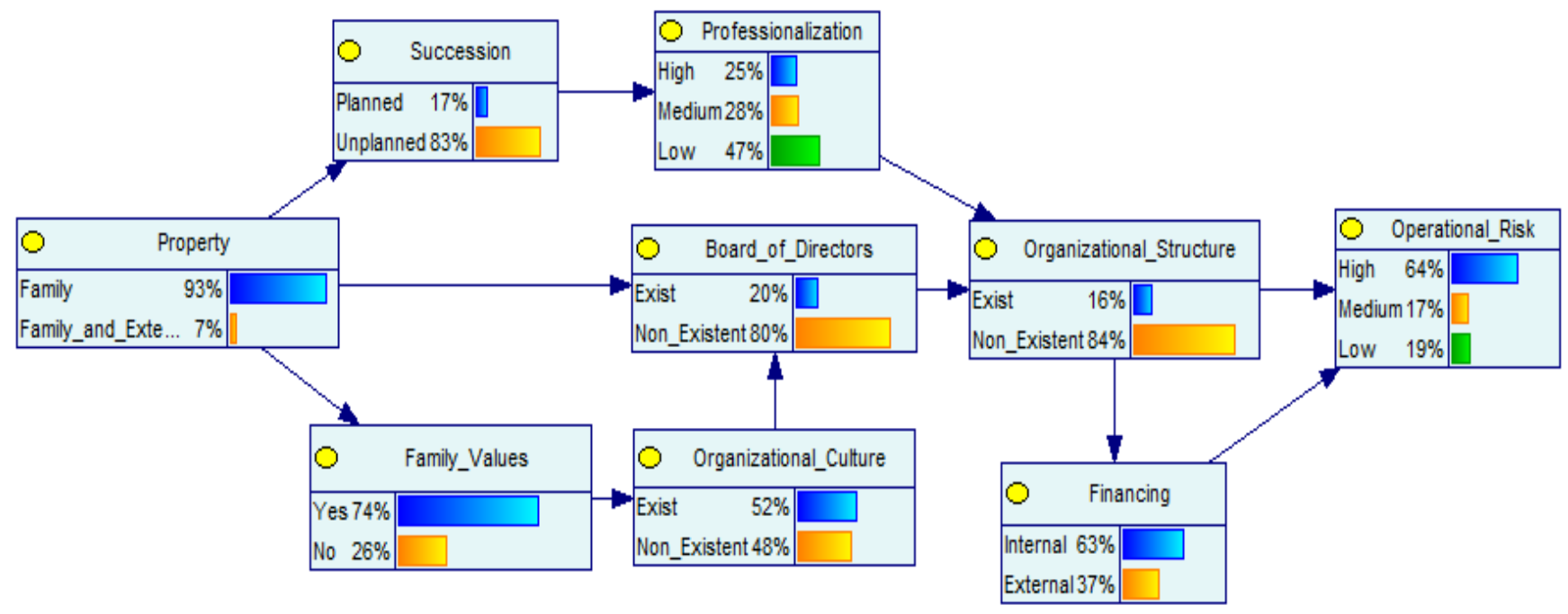

Source: own elaboration with GeNle software

\section{Scenario analysis}

One of the great advantages of the $\mathrm{BN}$ is the ability to perform calculations of new scenarios. For this research it was important to measure the impacts of the main variables with greater susceptibility to be changed in the short term in terms of business decisions seeking to reduce the OR to which they are exposed. It is important to highlight that modifications in the analysis variable imply an exogenous shock, so it has no direct relationship with the immediate superior node, and that is the reason why in the graphic model the arc that unites them disappears. Therefore, this condition will occur each time a variable is modeled by a controlled value. In the analysis of scenarios, one of the states of the variables is presented with a probability of $100 \%$ and the impact that this has on the analysis variable OR is evaluated. The objective is to know the variables in which the FB must focus its resources and efforts so that the high OR reaches the lowest level and the OR under the highest level. Ceteris paribus all the variables except Succession, the results show that if the power transition between generations is planned, a $5 \%$ decrease in the high probability of the OR is observed and an increase of the same 
percentage points in the probability of low OR (Figure 4); On the other hand, if there are no succession plans, the variations in the OR states have practically no variation (Figure 5).

Figure 4

Graphic model of planned succession

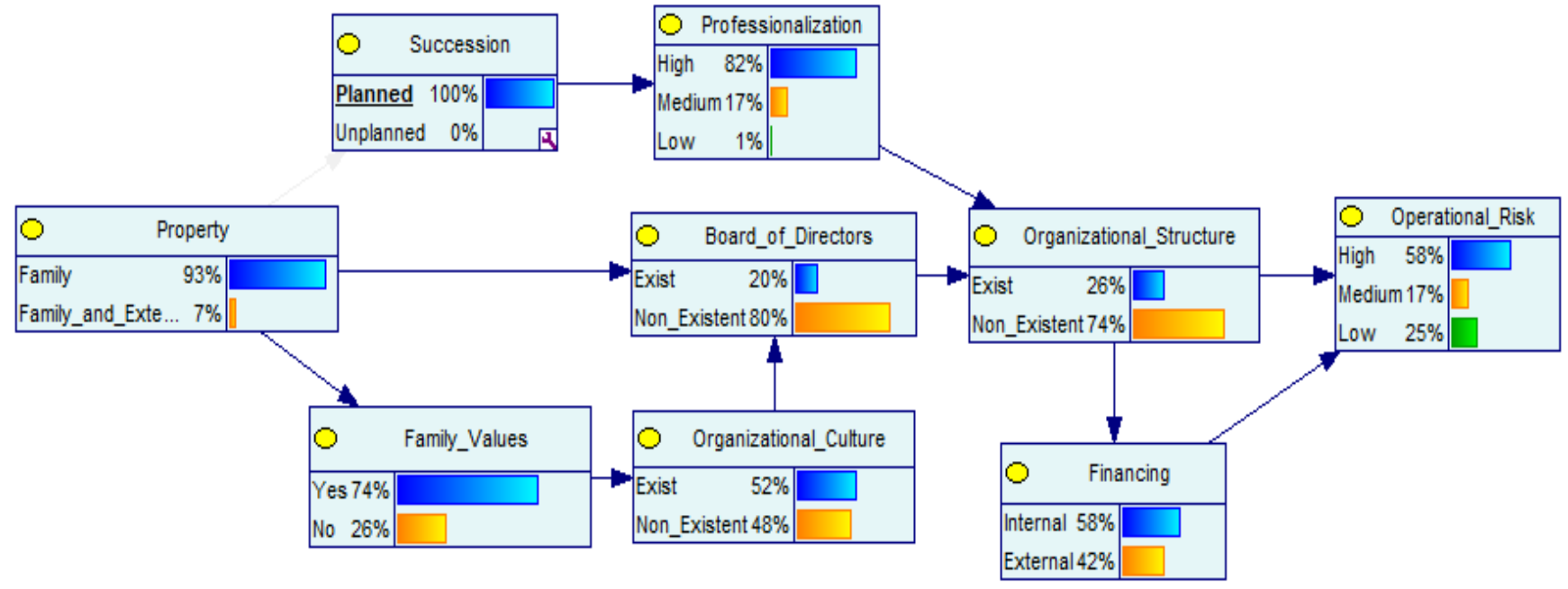

Source: own elaboration with GeNle software

In the case of staff professionalization, if it is high with a probability of $100 \%$, the probability of a high OR decreases by eight percentage points and the low OR increases by seven percentage points (Figure 6); at the opposite extreme, low professionalization increases the high OR by $5 \%$ and decreases the low OR at the same points (Figure 7). The analysis with average professionalization does not have significant changes in the analysis variable. When analyzing the Board of Directors, when this variable is analyzed with $100 \%$ probability of the existence of a board in the organization, the probability of the high OR decreases $20 \%$ and the probability of the low OR increases $19 \%$ (Figure 8 ). Conversely, by guaranteeing $100 \%$ probability that there is not a board in the family business, the probability of the high OR increases by $5 \%$ and in the same amount the low OR decreases (Figure 9).

Figure 5

Graphic model of unplanned succession
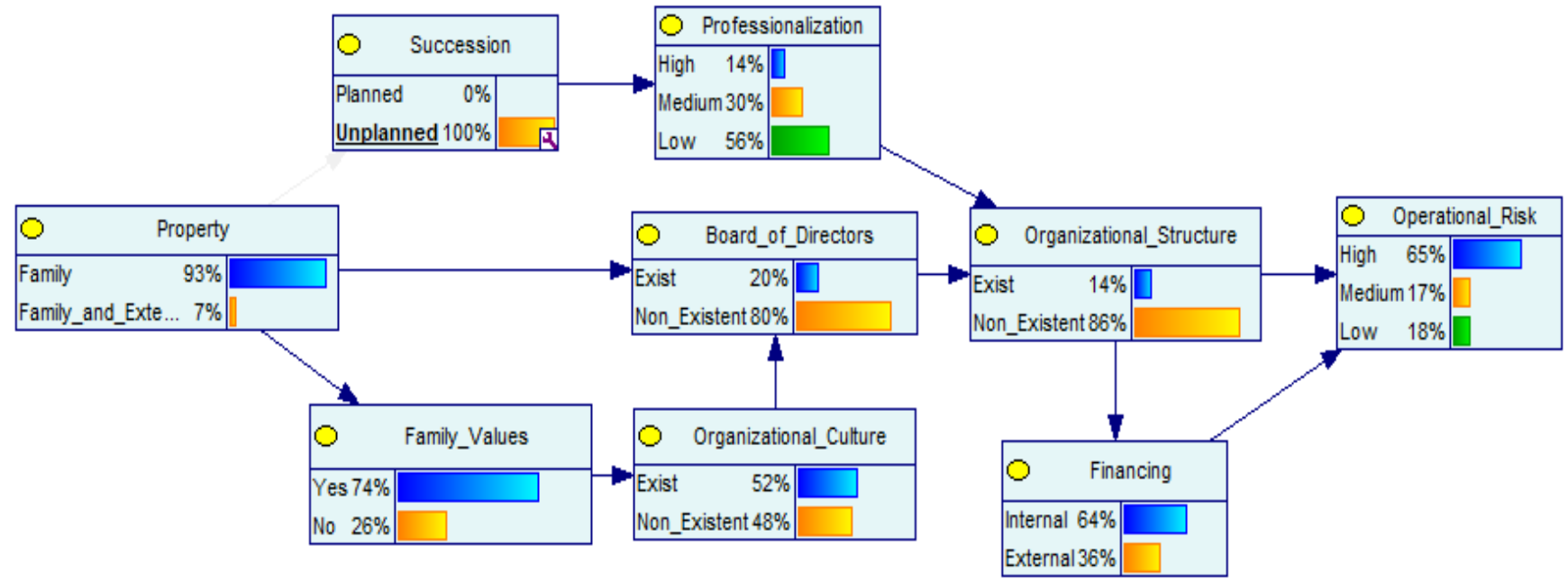

Source: own elaboration with GeNle software

In the case of staff professionalization, if it is high with a probability of $100 \%$, the probability of a high OR decreases by eight percentage points and the low OR increases by seven percentage points (Figure 6); at the 
opposite extreme, low professionalization increases the high OR by $5 \%$ and decreases the low OR at the same points (Figure 7).

Figure 6

High professionalization graphic model

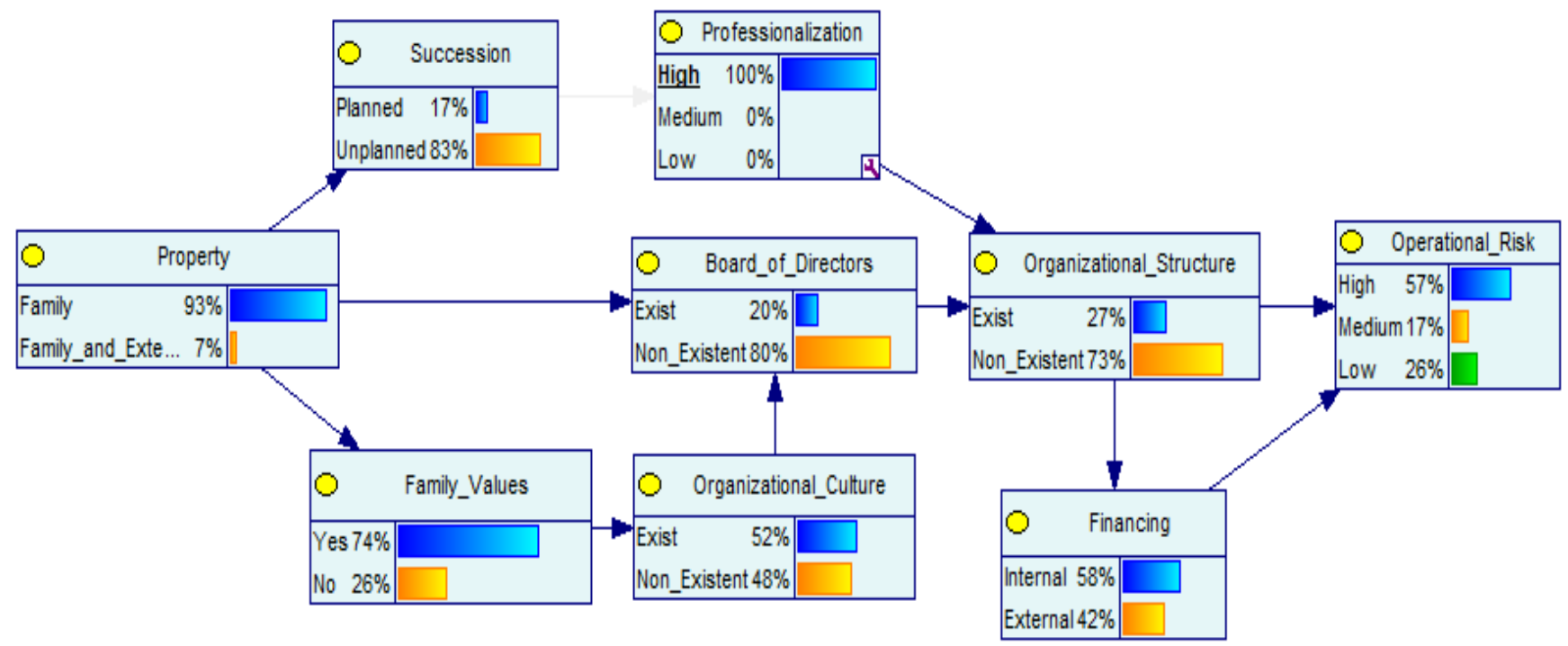

Source: own elaboration with GeNle software

Figure 7

Low professionalization graphic model

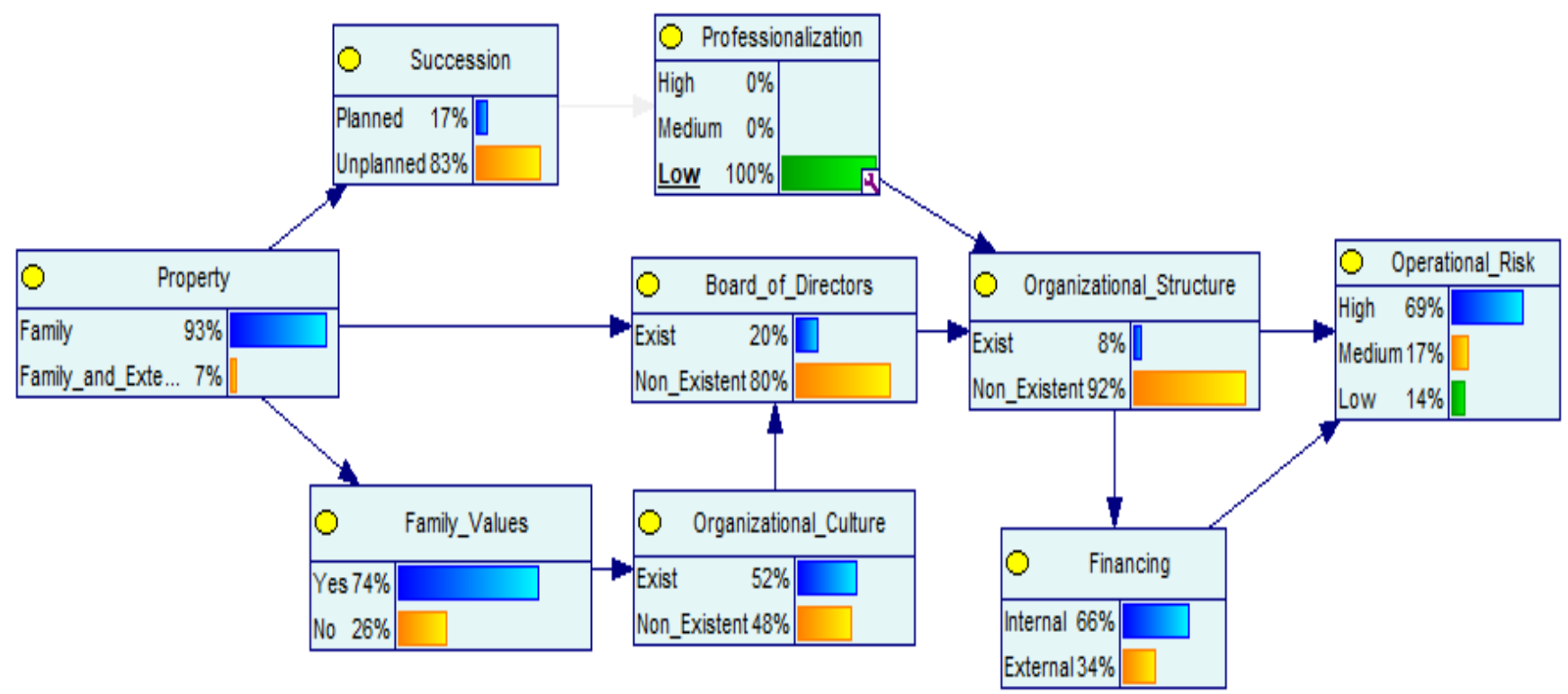

Source: own elaboration with GeNle software

The analysis with average professionalization does not have significant changes in the analysis variable. When analyzing the Board of Directors, when this variable is analyzed with $100 \%$ probability of the existence of a board in the organization, the probability of the high OR decreases $20 \%$ and the probability of the low OR increases $19 \%$ (Figure 8 ). Conversely, by guaranteeing $100 \%$ probability that there is not a board in the family business, the probability of the high OR increases by $5 \%$ and in the same amount the low OR decreases (Figure 9). 
Figure 8

Graphic model of existing board of Directors

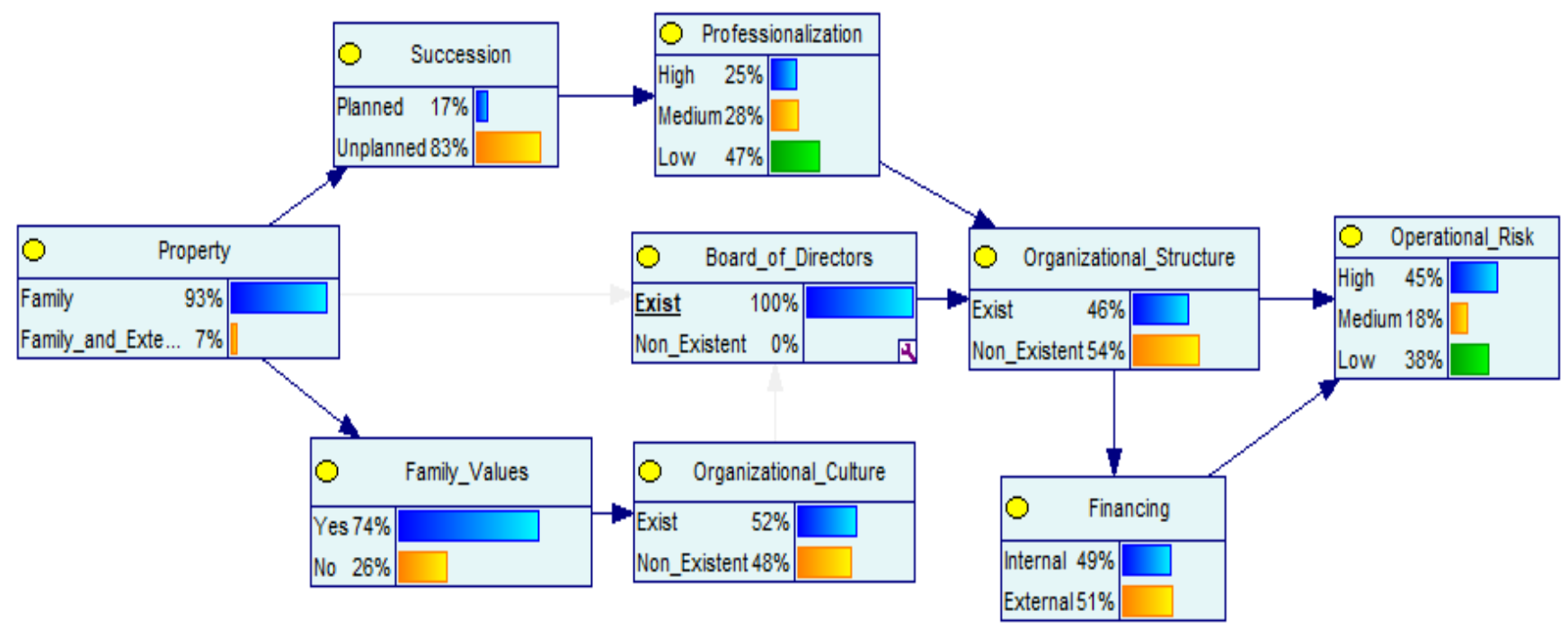

Source: own elaboration with GeNle software

Figure 9

Graphic model without the existence of a Board of Directors

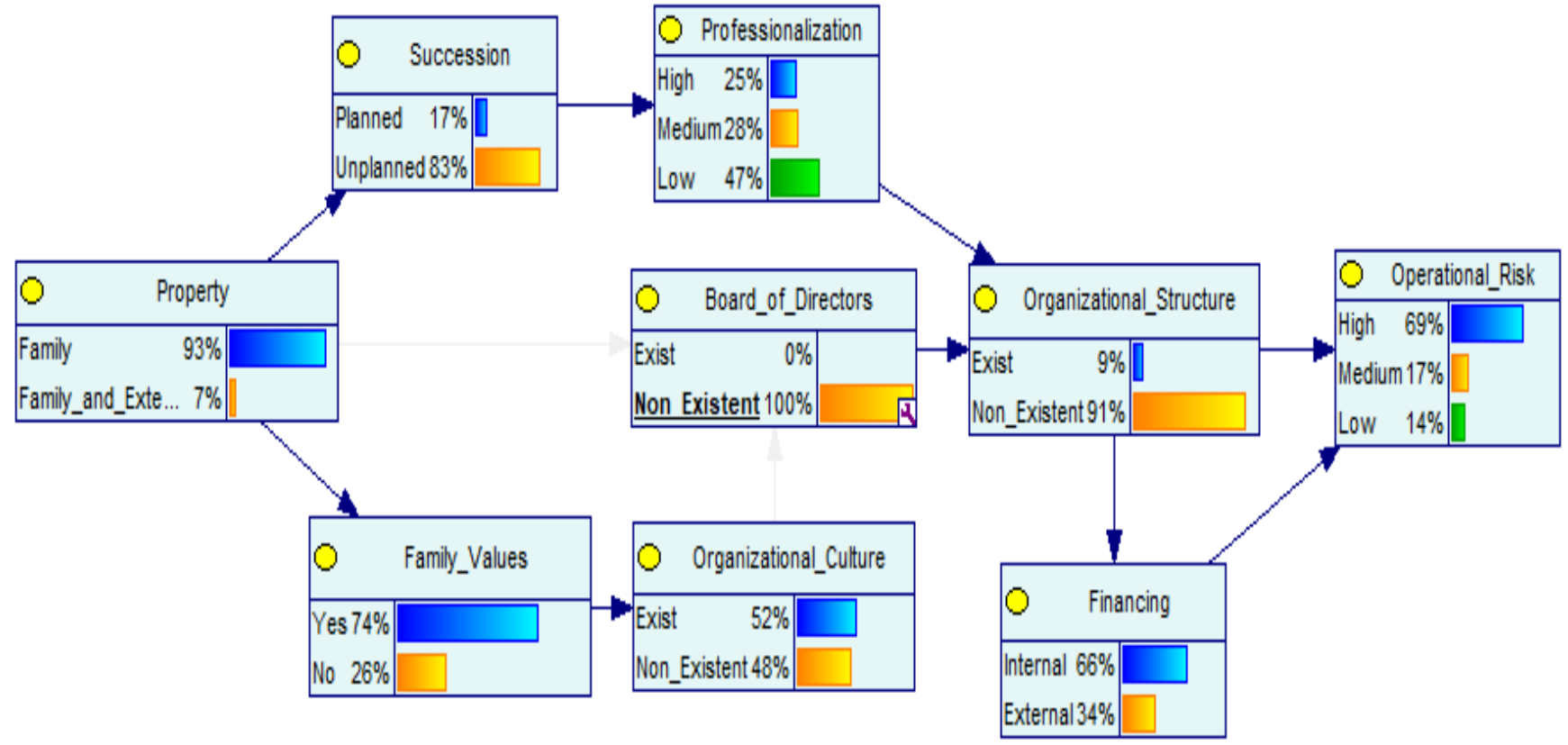

Source: own elaboration with GeNle software

Modifications to the variable named Organizational Structure imply large impacts on the analysis variable, OR. Guaranteeing the existence of an organizational structure implies having clearly defined the functions, responsibilities and roles of each of the employees, family and non-family, in the family business and represents a decrease of $55 \%$ in the high OR and an increase of $53 \%$ in the low OR (Figure 10). At the opposite side; the total absence of an organizational structure in the FB increases by $11 \%$ the high OR and decreases the low OR by $9 \%$ (Figure 11). This is the most significant variable of the analysis and in which more attention must be paid. The analysis of scenarios with the other variables of the Bayesian network was carried out but the impacts on the variable of interest, Operational Risk, were not significant, so their results are not shown. 
Figure 10

Graphic model of existing

Organizational Structure
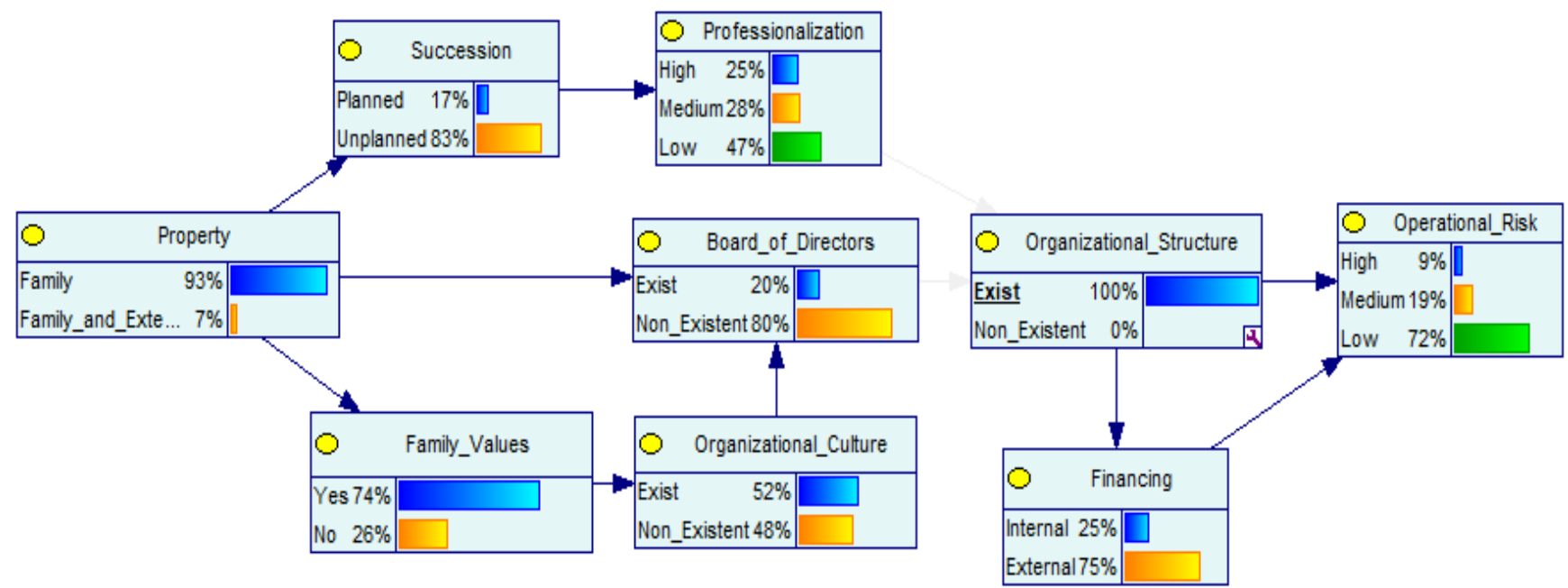

Source: own elaboration with GeNle software

Figure 11

Graphic model without the existence

of Organizational Structure
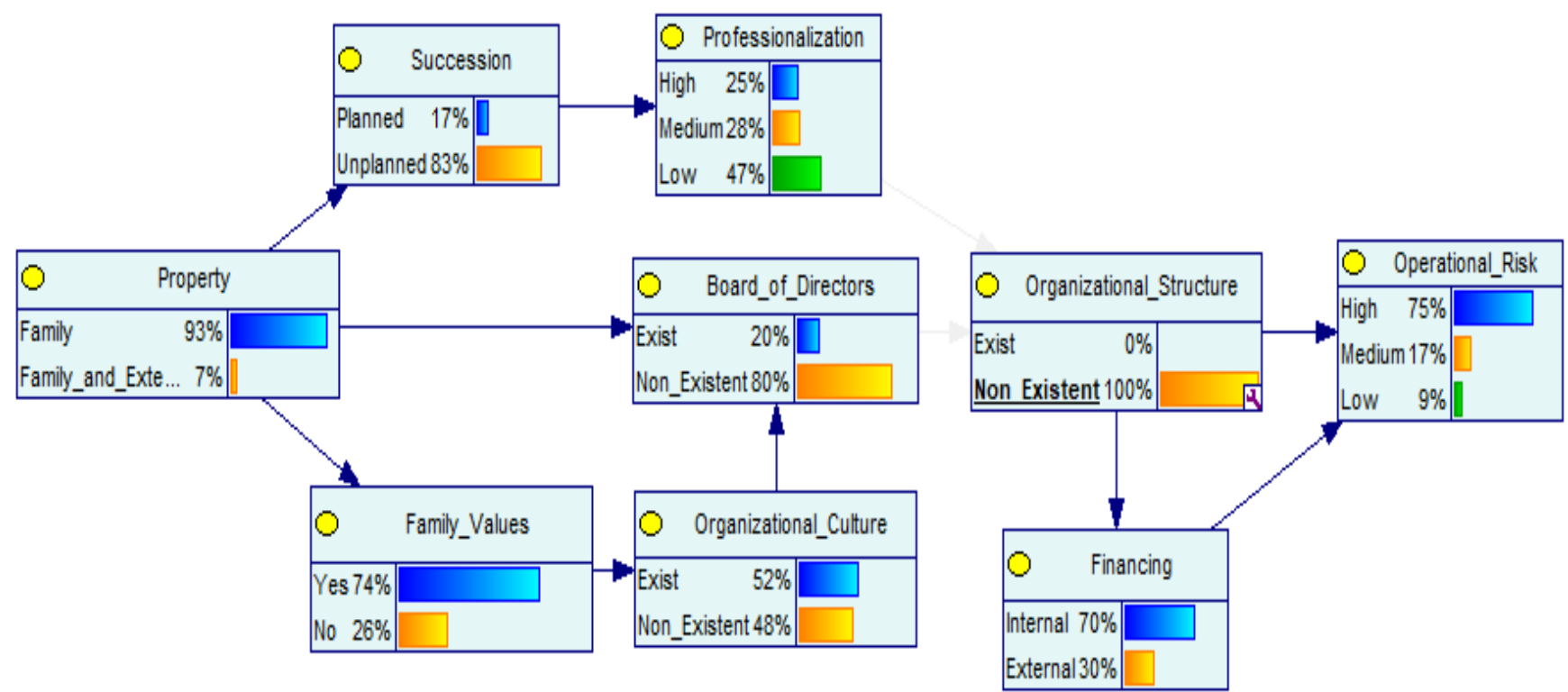

Source: own elaboration with GeNle software

\subsection{Brief considerations}

To consider that a company is standardized and on the way to institutionalization, it must mainly integrate and formalize three topics: 1) processes, 2) information systems, and 3) people trained according to the complexity of its operation. The three concepts are equally relevant and complementary in the pursuit of growth, permanence, and conservation of the company. These three concepts are also linked to the Operative Risk of the company that, according to Dávila, Ortiz and Cruz (2016), in recent years more entities, mainly financial, have placed special emphasis on quantifying it due to the great diversity of factors that they originate it as due to the 
lack of information on said factors. This need is especially visible in a private family business environment where obtaining information regarding processes, systems and people is difficult.

According to the results of this research, we were able to identify that the variable with the greatest impact on the operational risk of private FB is the Organizational Structure. When the functions, responsibilities, and roles of each and every one of the company's employees are clarified, the probability that a company has a high risk is only $9 \%$. This scenario is the one that would give more certainty about the future of the company. This variable provides the basis to institutionalize the organization and to prevent the Family Business from being managed informally. According to what Aira (2016) expressed, when there is an absence of clear limits and a balance between the entities that participate in the company, the stability and borders of the system are put at risk. Also, professionalization and the existence of a Board of Directors are phenomena that also affect the operational risk. These two elements may be those that tend to have less presence in the configuration of the FB. However, as the studies expressed as Martínez et al. (2007), Sharma et al. (2102) and Stewart and Hitt (2012), they are the private FBs on which we must focus investigations to understand the reasons why their financial performance is lower than in non-family companies.

Analyzing these two variables from the stage of complete absence can be misleading. If a family business, which does not have professionalization schemes or does not have a Board of Directors, compares its operational risk against the baseline scenario, it could be wrong to consider that these variables are elements of little relevance. In the base scenario, a company has a high operational risk probability of 64 per cent. According to the results of this study the probability of a high operational risk would only grow by five per cent, if there are none professionalization schemes or none board, therefore, a family entrepreneur could conclude that more than helping, the fact of starting to professionalize the company or create a board, would hinder the dynamism and control it has over the family business. However, the vision should be different and better observe the benefits that would bring to the family business to strengthen these two variables in the operational risk category. Having professionalization schemes would help the probability of high operational risk decrease by eight percentage points and, more importantly, having a Board of Directors that defines the strategy and long-term plans, would help reduce the likelihood of risk operating high by 20 percentage points. The attractiveness of a private family business with lower levels of operational risk increases considerably, as well as access to new financing alternatives, to more qualified suppliers and to talented executives attracted by better constituted companies.

When private FB focus their efforts on improving their organizational structure, their professionalization schemes and the formalization of their Board of Directors, a more successful environment is generated by integrating the complex and dynamic social system of the family business. As expressed in the study by Gersick et al. (1997), successful FB facilitate the optimization of subsystems by creating policies in which family and nonfamily employees, together with the shareholders, feel responsible for the economic resources of the company and the family. It should be noted that the objective of professionalizing the family business and providing it with a board does not mean that it loses its family status or that family members take a back seat. According to Castrillo and San Martín (2007), family involvement in the ownership and management of the business provides advantages, since in a family business where owners and managers with family ties coincide, it can be more efficient given that family ownership allows convergence of interests between management and shareholders, which leads to the maximization of the value of the company.

Regarding the succession, although the results show that if the transition of power between generations is planned, only a five per cent decrease in the high probability of operational risk is observed, the succession is one of the most critical elements for family businesses. Manzano and Ayala (2002) point out that there are few companies that survive the transition between generations. Recall that only between 25 and 30 per cent of the FB last from the first to the second generation and that between nine per cent and 15 per cent, only six per cent 
or less manage to pass from the third to the fourth generation, see Neubauer and Lank (1998). As part of what will be a long-term project, it is necessary to identify early on who will guide the company in the next generation and ensure that they have the training and skills for the job. If the person is not competent enough to deserve the position on their own merits, what might happen is that it weakens the whole organization. The FB can improve their probability of survival and growth if they implement the correct organizational structures, if they promote professionalization schemes, if they decide to form a Board of Directors, and if they begin the educational process of successive generations as soon as possible.

\section{Conclusions}

When analyzing the determinants of Operational Risk within a sample of Family Businesses, based on information obtained by a group of experts surveyed, it is found that the variable with the greatest impact on the Operational Risk of the private FB is the Organizational Structure. When the functions, responsibilities, and roles of each and every one of the company's employees are clarified, the probability that a company has a high risk is only nine per cent. This scenario is the one that gives more certainty about the future of the company. Likewise, professionalization and the existence of a Board of Directors are phenomena that also affect in a positive way to reduce the OR. With respect to the succession, the results show that if the power transition between generations is planned, a five per cent decrease in the probability of generating high OR is observed.

For the analyzed sample, the FB can improve their probability of survival and growth if they implement the correct organizational structures, if they promote professionalization schemes, if they decide to form a Board of Directors and if they begin the educational process of the successive generations as soon as possible. The fundamental scope of the present investigation is that a Bayesian network was designed that incorporates and relates the risk factors already described in section IV, which allowed quantifying the degree of Operational Risk. Among the main limitations is that any variation to the Bayesian network defined by experts could alter the magnitude and meaning of the results. Moreover, the results depend on the quantification of the Bayesian Network that is based on the information obtained from the experts. Consequently, the pending agenda will be to obtain statistical information on the variables defined and incorporate them into the Bayesian Network defined in the present investigation. Also, verify that at least the sense of the causalities found is maintained.

\section{References}

Aira, M.R. (2016). La Sucesión Exitosa en Empresas Familiares. Revista Científica Electrónica de Ciencias Humana, 33, 82-104.

Allouche, J., Amann, B., Jaussaud, J., \& Kurashina, T. (2008). The Impact of Family Control on the Performance and Financial Characteristics of Family Versus Nonfamily Businesses in Japan: A Matched-Pair Investigation. Family Business Review, 315-329.

Anderson, R. C., \& Reeb, D. M. (2003). Founding-Family Ownership and Firm Performance Evidence from the S\&P 500. The Journal of Finance, 1301-1328.

Bañeguil Palacios, T., Barroso Martínez, A. and Tato Jiménez, J. (2011). Profesionalizarse, emprender y aliarse para que la empresa familiar continue. Revista de Empresa Familiar, 1, 27-41

Barroso, A. (2014). Por qué desaparecen las empresas familiares extremeñas. Revista digital para estudiantes de Geografía y Ciencias Sociales, 5, 98-132.

Beltrán, M., Muñoz, A. \& Muñoz, A. (2014). Redes bayesianas aplicadas a problemas de credit scoring. Una aplicación práctica. Cuadernos de economía, 2014; 37-73. 
Carney, M., Van Essen, M., Gedajlovic, E. R., \& Heugens, P. P. (2013). What Do We Know About Private Family Firms? A Meta-Analytical Review. Entrepreneurship Theory and Practice, 513-544.

Castrillo, L.A. \& San Martín, J.M., (2007). La propiedad familiar como mecanismo de gobierno disciplinador de la dirección en las empresas mexicanas: Una evidencia empírica, Circular Única de Bancos (CUB), Secretaría de Hacienda y Crédito Público, 2005

Chonawee S., Kenyon, C., \& Heusler, L. (2006). Cause to Effect Operational Risk Quantification and Management. Palgrave Macmillan Journals, 8, 16-42.

Cochran, T. (1959). The Puerto Rican businessman. Philadelphia: University of Pennsylvania.

Colli, A. (2003). The History of Family Business 1850-2000. Cambridge: Cambridge University Press.

Corbetta, G. (1995). Patterns of Development of Family Business in Italy. Family Business Review, 255-265.

Cowell, R. G., Dawid, P., Lauritzen, S. \& Spiegelhalter, D. (1999). Probabilistic Networks and Expert Systems. New York: Springer-Verlag.

Cowell R.G., Verrall, R.J. \& Yoon, Y.K. (2007). Modeling Operational Risk with Bayesian Networks. The Jorunal of Risk and Insurance, Vol. 74 No. 4. 795-827.

Dávila, G., Ortiz, F. \& Cruz, F. (2016). Cálculo del valor en riesgo operacional mediante redes bayesianas para una empresa financiera. Contaduría y Administración, 61, 176-201

Davis, S. (1968). Entrepreneurial succession. Administrative Science Quarterly, 13, 402-416.

Esquivel, L. \& Aguilar, H. (2002). Los valores familiares: una aproximación teórica y metodológica. Educación y Ciencia, 6, 45-52.

Fernandez, E., Junquera, B., \& Ordiz, M. (2003). Organizational Culture and human Resources in Environmental Issue: A Review of Literature. International Journal of Human Resource Management, 14, 634-656.

Gallo M. A. (1995). Empresa familiar. Textos y casos. Barcelona: Praxis.

Gersick, K.; Davis, J.; McCollom, M; Lansbersg, I. (1997). Generation to Generation: Life Cycles of the Family Business. USA: Harvard Business School Press.

Giménez, J. (2002). Riesgo y eficiencia en la empresa familiar Boletín de Estudios Económicos, 57, 395-432.

Gueye, S., \& Simon, E. (2010). Is the Family Business a Safer Type of Governance in Time of Crisis? Problems and Perspectives in Management, 23-29.

IFC - Banco Mundial. (2011). Manual IFC de gobierno de empresas familiares. Corporación Financiera Internacional, Banco Mundial. Washington

Instituto Nacional de Estadística Geografía e Historia (INEGI), 2020, Directorio de Empresas y Establecimiento, retreived May 17th of 2020. https://www.inegi.org.mx/temas/directorio

Kets de Vries, M.F. (1993). The entrepreneurial personality: A person at the crossroads. Journal of Management Studies, 14, 34-57.

Kuratko, D., Foss, H. \& Vanalst, L. (1994). 1rs estate freeze rules: implications for family business succession planning. Family Business Review, 1, 61-71.

Leach, P. (2009). La empresa familiar. Buenos Aires: Ediciones Granica Vergara.

Le Breton-Miller, I., \& Miller, D. (2006). Why Do Some Family Businesses Out-Compete? Governance, LongTerm Orientations, and Sustainable Capability. Entrepreneurship Theory and Practice, 731-746. 
Madsen, A. L., \& Kjærulff, U. B. (2013). Bayesian Networks and Influence Diagrams: A Guide to Construction and Analysis. New York: Springer.

Manzano, G. \& Ayala, J. (2002). Sucesión en la empresa familiar: Algunas claves del éxito. Boletín de Estudios Económicos, 57, 433-449.

Martínez, J. I., Stöhr, B. S., \& Quiroga, B. F. (2007). Family Ownership and Firm Performance: Evidence From Public Companies in Chile. Family Business Review, 83-94.

Martin-Reyna, J. S., \& Duran-Encalada, J. A. (2012). The Relationship Among Family Business, Corporate Governance and Firm Performance: Evidence From the Mexican Stock Exchange. Journal of Family Business Strategy, 106-117.

Masulis, R.; Kien, P. \& Zein, J. (2011). Family Business Groups around the world: Financing Advantages, Control Motivations and Organizational Choices. Review of Family Business, Vol. 24, pp. 3556-3600

Mitchell, T.M. (1997). Machine Learning. McGraw-Hill

Moore, W. (1951). Industrial relations and the social order. New York: Macmillan

Narver, J. \& Slater, S. (1990) The Effect of a Market Orientation on Business Profitability. Journal of Marketing, 54, 20-35.

Neubauer, F. \& Lank, A. (1998). La empresa familiar. Como dirigirla para que perdure. Barcelona: Deusto.

Neil, M., Fenton, M., \& Tailor, M. (2005). Using Bayesian Networks to Model Expected and Unexpected Operational Losses. Risk Analysis, 963-972.

Poza Ernesto J. (2005). Empresas Familiares. México: Thomson Learning.

Ramírez, M., and M. Fonseca. (2010). Building social capital across generations. Family Enterprise Research Conference, México.

Robbins, S. \& Coulter, M. (2000). Administration. México: Prentice Hall

Sharma, P., \& Carney, M. (2012). Value Creation and Performance in Private Family Firms: Measurement and Methodological Issues. Family Business Review, 233-242.

Sharma, P., Chrisman, J. J., \& Gersick, K. E. (2012). 25 Years of Family Business Review: Reflections on the Past and Perspectives for the Future. Family Business Review, 5-15.

Soto Maciel, A. (2013). La empresa familiar en México. Situación actual de la investigación. Contaduría y Administración, 58, 135-171.

Stewart, A., \& Hitt, M. A. (2012). Why Can't a Family Business Be More Like a Nonfamily Business? Modes of Professionalization in Family Firms. Family Business Review, 58-86.

Tagiuri, R. \& Davis, J.A. (1996) Bivalent attributes of the family firm. Family Business Review, 2, 199-208.

Ward John (2007). El éxito en los negocios de familia. Colombia: Norma.

Esta obra está bajo una Licencia Creative Commons Attribución-NoCommercial 4.0 International

(c) $)$ EY-NO 